Braendle, D. H., Gardiner, Beth \& Szybalski, W. (1959). J. gen. Microbiol. 20, $442-450$

\title{
Heterokaryotic Compatibility in Streptomyces
}

\author{
BY D. H. BRAENDLE*, BETH GARDINER† AND W. SZYBALSKI $†$ \\ Institute of Microbiology, Rutgers, The State University, New Brunswick, \\ New Jersey, U.S.A.
}

SUMMARY : The compatibility system in Streptomyces fradiae may be characterized as follows. When $10^{8}$ conidia of each of two freshly isolated auxotrophic mutants are mated on minimal medium, a small number, usually 1 to 10, of 'primary" heterokaryotic colonies appear (low-frequency mating, LFM). On the other hand, when 'secondary parental isolates' (derived from the conidia produced by 'primary" heterokaryons) are mated, the frequency of heterokaryon formation is increased by a factor of several thousand. This high-frequency mating (HFM) is a reasonably stable property, decreasing (or increasing) in a stochastic manner, only after a considerable number of subcultures. A mutational origin is therefore postulated for the HFM and LFM isolates, which must be endowed with variable cultural fitness causing diverse population shifts upon subculture. More effective anastomosis, not increase in residual growth of the 'secondary parental isolates', appears to be responsible for HFM. No interspecific crosses were successful, even when an HFM tester stock was used, but heterokaryotic interaction between independently isolated auxotrophic mutants derived from the same line of $S$. fradiae seemed to increase when an HFM strain was one of the partners.

The formation of prototrophic heterokaryons between auxotrophic mutants of Streptomyces fradiae was described by Braendle \& Szybalski (1957). The frequency of heterokaryosis between compatible strains varied over a wide range, but was fairly reproducible for a particular parental combination during the limited period of study. Several months after these initial observations, some of the matings were repeated. In the intervening period, the auxotrophic mutants had been maintained in storage at $4^{\circ}$, undergoing several transfers and purification by single cell isolation. It was observed, in the case of the two mutants $6 \mathrm{~F} \mathrm{4-1} \mathrm{(requiring} \mathrm{methionine} \mathrm{+} \mathrm{isoleucine} \mathrm{and} 6 \mathrm{~F} \mathrm{5-16}$ (requiring histidine + arginine), that the frequency of heterokaryosis on minimal agar had decreased from the earlier value of 100-200 colonies to less than one/inoculum of $10^{8}$ conidia of each parent. On the other hand, re-isolation of the parental-type strains ('secondary parental isolates') from the conidia produced by these infrequent heterokaryons, and their subsequent mating, resulted in an increase in the frequency of heterokaryosis by a factor as high as 5000. This marked difference in mating ability suggested the possible existence of compatibility factors which controlled heterokaryotic mating.

Though the heterokaryotic phenomenon has received considerable attention (Dodge, 1942; Hansen, 1938; Beadle \& Coonradt, 1944; Pontecorvo, 1946;

* Present address : Abbott Laboratories, North Chicago, Illinois, U.S.A.

$\dagger$ Present address: Squibb Institute for Medical Research, New Brunswick, New Jersey, U.S.A. 
Ishitani \& Sakaguchi, 1956), only a few references have been made to the existence of preferential mating in heterokaryon formation (Papazian, 1950; Raper \& San Antonio, 1954). The demonstration of heterokaryosis in many strains of Streptomyces has only recently been reported (Bradley \& Lederberg, 1956; Szybalski \& Braendle, 1956). The function of this phenomenon in the process of genetic recombination in the streptomycetes has been described for Streptomyces coelicolor (Sermonti \& Spada-Sermonti, 1956) and for $S$. fradiae (Braendle \& Szybalski, 1957). The following study was undertaken for the purpose of ascertaining the physiological and genetic basis of the striking difference in mating ability between auxotrophic mutants and their 'secondary parental isolates'.

\section{METHODS}

Stock cultures of mutants were maintained on Difco nutrient agar slopes enriched with $10 \mu \mathrm{g}$. required amino acid $/ \mathrm{ml}$. A defined minimal medium prepared with thoroughly washed agar (Braendle \& Szybalski, 1957) was used in all mating experiments.

Auxotrophic mutants of Streptomyces fradiae 3535, S. griseus 3475, and $S$. venezuelae 3625 (from the culture collection of the Institute of Microbiology) were isolated after ultraviolet irradiation of the wild-type strains. The auxotrophic mutant, 14D1, of S. coelicolor was kindly sent to us by Dr G. Sermonti of the Istituto Superiore di Sanità, Rome.

Compatible strains were mated on minimal agar as described by Braendle \& Szybalski (1957), and from the resulting heterokaryons 'secondary parental' strains were isolated as follows. Conidia were collected from the surface of the heterokaryotic colony with a wire loop and streaked on the surface of nutrient agar (NA) plates so as to obtain well-isolated colonies. The nutritional requirements of individual resulting colonies were determined and in all cases were identical with those of either parent. Representative colonies of both parental types were chosen at random and streaked on supplemented nutrient agar slants for future use. The 'secondary parental' strains thus isolated were designated by a capital letter after the code number of the primary parental strain; e.g. the two 'secondary parental' types isolated from a particular heterokaryotic colony composed of mutants 6 F 4-1 and 6 F 5-16 were desig-

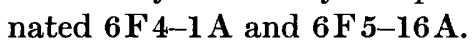

For the preparation of conidial suspensions in the mating experiments, conidia of suitable parental strains were harvested from slope or plate cultures and suspended in $5 \mathrm{ml}$. saline, to which Triton WR-1339 (Winthrop-Stearns Inc.) was added in a final concentration of $0.05 \%(\mathrm{w} / \mathrm{v})$. The suspensions were thoroughly agitated and filtered through Whatman No. 2 filter paper. The number of viable conidia was subsequently measured by plating appropriate dilutions on complete media and counting the number of colonies which appeared after 4 days of incubation at $28^{\circ}$. Heterokaryons were synthesized by spreading a mixture of $0.1 \mathrm{ml}$. of each of the appropriate parent conidial suspensions on the surface of a minimal agar plate. Heterokaryotic colonies were counted after incubation for 8 days at $28^{\circ}$. 
The frequency of heterokaryosis was determined by calculating the ratio: average number of heterokaryotic colonies which appeared on the plates to number of conidia in the inoculum of the minority parent. This ratio, which will be referred to as the 'heterokaryotic frequency', remained reasonably constant for a particular parental combination when the inoculum varied between $10^{7}$ and $10^{9}$ conidia/plate.

To determine spontaneous reversion rates, each suspension of parental conidia was also plated separately on minimal agar plates, which were inspected for colony formation after incubation for 8 days.

A test for syntrophy was performed by streaking the mutant strains on minimal agar in close proximity to each other without permitting direct contact. Should cross-feeding occur under these conditions, growth would be expected to appear in regions where the streaks were most closely associated.

\section{RESULTS}

Heterokaryotic frequency of 'primary, secondary, and tertiary parental isolates'

Strains 6F 4-1 (meth ${ }^{-}$, isoleu/leu-) and 6F5-16 (hist-, arg $^{-}$), together with their 'secondary parental isolates' $(6 \mathrm{~F} 4-1 \mathrm{~A}, 6 \mathrm{~F} 4-1 \mathrm{~B}, 6 \mathrm{~F} \mathrm{5-16A}$, and $6 \mathrm{~F} 5-16 \mathrm{~B}$ ) bearing the respective parental deficiencies and derived from heterokaryons in the manner described in Methods, were mated in all possible combinations. The absence of growth on the control plates indicated that reverse mutation to prototrophy, and syntrophy between the parental auxotrophs, were negligible factors in these experiments. Table 1 summarizes the results, expressed as the frequency of heterokaryon formation. The recorded number of heterokaryotic colonies resulting from each mating is an average of four plates prepared simultaneously. A sharp increase in the frequency of heterokaryosis invariably resulted when the corresponding 'secondary parental isolates' were substituted for the parental auxotrophs. This held true even when the former originated from different heterokaryotic colonies of the same cross.

To determine whether strains with still higher frequencies of heterokaryosis could be developed by successive isolation of 'secondary' and 'tertiary' parental types from heterokaryons, conidial isolates were obtained from

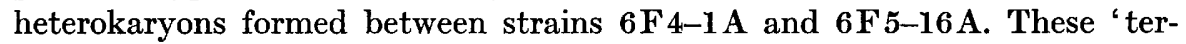
tiary parental isolates', when mated, displayed the same order of heterokaryosis as did strains 6F 4-1 Aand 6F 5-16 A.

\section{Germination of conidia and residual growth}

It was conceivable that the observed increase in frequency of heterokaryosis might be the result of selection for conidia with higher germination capacity or greater residual mycelial development, thereby increasing the possibility of direct contact between the parental mycelia on the surface of the selective medium. To test this possibility, strains 6 F 4-1, 6F 5-16, 6F 4-1 A, 6F 5-16 A, and $6 \mathrm{F5}-16 \mathrm{~B}$ were plated separately and in compatible combination on a 
thin layer of minimal agar. Microscopic observation failed to show any noticeable differences in conidial germination and residual mycelial development between strain $6 \mathrm{~F} \mathrm{4-1} \mathrm{and} \mathrm{its} \mathrm{high-frequency} \mathrm{derivative} 6 \mathrm{~F} 4-1 \mathrm{~A}$, when these strains were cultivated separately. Conidial germination for both strains was about $90 \%$, with the length of the residual hyphal growth varying between 0.6 and $12 \mu$ at $24 \mathrm{hr}$. Growth terminated in $48 \mathrm{hr}$. with the development of small branched tangles of mycelium. Strains 6F5-16, 6F 5-16 A, and

Table 1. Frequency of heterokaryosis between two auxotrophic mutants of Streptomyces fradiae and their 'secondary parental isolates'

The 'secondary parental isolates' are indicated by the letter $\mathrm{A}$ or $\mathrm{B}$ following the symbol of the auxotrophic mutant 6F4-1 requiring methionine +isoleucine/leucine; and 6F 5-16 requiring histidine + arginine.

\begin{tabular}{|c|c|c|c|}
\hline Strains & $\begin{array}{c}\text { Inoculum (no. of } \\
\text { conidia/plate) }\end{array}$ & $\begin{array}{c}\text { No. of } \\
\text { heterokaryotic } \\
\text { colonies/plate* }\end{array}$ & $\begin{array}{l}\text { Heterokaryotic } \\
\text { frequency } \times 10^{8} \dagger\end{array}$ \\
\hline $\begin{array}{l}6 \mathrm{~F} \mathrm{4-1} \\
6 \mathrm{~F} 5-16\end{array}$ & $\begin{array}{l}4.7 \times 10^{7} \\
8.0 \times 10^{7}\end{array}$ & $0 \cdot 25$ & 0.53 \\
\hline $\begin{array}{l}6 F 4-1 \\
6 F 5-16 A\end{array}$ & $\begin{array}{l}4.7 \times 10^{7} \\
1.5 \times 10^{7}\end{array}$ & $4 \cdot 2$ & $28 \cdot 0$ \\
\hline $\begin{array}{l}6 \mathrm{~F} 4-1 \\
6 \mathrm{F5}-16 \mathrm{~B}\end{array}$ & $\begin{array}{l}4.7 \times 10^{7} \\
4.9 \times 10^{7}\end{array}$ & $3 \cdot 5$ & $7 \cdot 5$ \\
\hline $\begin{array}{l}6 F 4-1 A \\
6 F 5-16\end{array}$ & $\begin{array}{l}3.8 \times 10^{8} \\
8.0 \times 10^{7}\end{array}$ & $75 \cdot 0$ & $95 \cdot 0$ \\
\hline $\begin{array}{l}6 F 4-1 B \\
6 F 5-16\end{array}$ & $\begin{array}{l}2.6 \times 10^{9} \\
1.5 \times 10^{10}\end{array}$ & 155 & $5 \cdot 9$ \\
\hline $\begin{array}{l}6 F 4-1 A \\
6 F 5-16 A\end{array}$ & $\begin{array}{l}3.8 \times 10^{8} \\
1.5 \times 10^{7}\end{array}$ & 521 & 3500 \\
\hline $\begin{array}{l}6 F 4-1 A \\
6 F 5-16 B\end{array}$ & $\begin{array}{l}4.6 \times 10^{7} \\
1.5 \times 10^{8}\end{array}$ & 2494 & 5400 \\
\hline $\begin{array}{l}6 F 4-1 B \\
6 F 5-16 A\end{array}$ & $\begin{array}{l}2.6 \times 10^{9} \\
3.8 \times 10^{9}\end{array}$ & 1655 & 63 \\
\hline $\begin{array}{l}6 F 4-1 B \\
6 F 5-16 B\end{array}$ & $\begin{array}{l}1.2 \times 10^{7} \\
4.9 \times 10^{7}\end{array}$ & 637 & 5300 \\
\hline
\end{tabular}

* Average number of heterokaryotic colonies on four plates.

$\dagger$ Ratio of the number of heterokaryotic colonies to the number of conidia of the minority parent in the inoculum (cf. Methods).

6F 5-16B appeared identical in their conidial germination and residual hyphal growth. Conidial germination for these strains amounted to 10-20\% after incubation for $39 \mathrm{hr}$. The process of germination was $90 \%$ complete after 6 days of incubation, with hyphal length varying between 0.5 and $10 \mu$; a small amount of branching was observed in strain $6 \mathrm{~F} \mathrm{5-16B}$ at this time. Further incubation of these cultures failed to promote growth beyond the 6-day limit.

When the strains were mixed in pairs, 6F4-1 and 6F5-16, 6F 4-1 $\mathrm{A}$ and $6 \mathrm{~F} 5-16 \mathrm{~A}, 6 \mathrm{~F} 4-1 \mathrm{~A}$ and $6 \mathrm{~F} 5-16 \mathrm{~B}$, germination and mycelial development appeared to be limited to that previously observed with strains 6F4-1 and 6 F 4-1 A. In $39 \mathrm{hr}$. conidial germination varied from 70 to $80 \%$, with hyphal development approximately $12 \mu$ in length and considerable branching 
apparent. The growth of the mixed culture of strains $6 \mathrm{~F} 4-1 \mathrm{~A}$ and $6 \mathrm{~F} \mathrm{5-16B}$ was considerably advanced at this time, showing dense centres of mycelial growth which were ultimately to become heterokaryotic colonies. A few ungerminated conidia were apparent in matings between $6 \mathrm{~F} 4-1$ and $6 \mathrm{~F} \mathrm{5-16}$ after 6 days; however, growth was too extensive in the other mixed cultures for detailed observations. The number of heterokaryotic colonies on the plates observed microscopically varied from three colonies in the $6 \mathrm{~F} \mathrm{4-1/6 \textrm {F } \mathrm { 5 } - 1 6}$ mating to almost confluent colonial growth in the $6 \mathrm{~F} 4-1 \mathrm{~A} / 6 \mathrm{~F} \mathrm{5-16 \textrm {A } \text { matings }}$ and $6 \mathrm{~F} 4-1 \mathrm{~A} / 6 \mathrm{~F} 5-16 \mathrm{~B}$ matings, a result which correlated well with that obtained when the strains were previously mated, as shown in Table 1.

\section{Stability of heterokaryotic compatibility}

The stability of the condition of high frequency of heterokaryotic compatibility was tested under various conditions. HFM strains were stored for 6 months on nutrient agar slopes at $4^{\circ}$. Upon subsequent testing, they exhibited undiminished frequencies of heterokaryotic interaction.

The effect of serial transfer on the stability of the high-frequency of mating was also evaluated. The results obtained in the first experiment are summarized in Table 2, Expt. 1. The HFM strains were transferred from slope to slope every 5 days by mass mycelial inoculation. After every third transfer, crosses were made. Following nine serial transfers, the frequencies of heterokaryosis were markedly decreased. After 12 transfers, there was essentially no difference in mating ability between the 'secondary parental isolates' and the original auxotrophs.

Further experiments were initiated to ascertain whether the change from low- to high-mating frequency follows a single or multiple step pattern. If the first alternative were correct, it could then be postulated that different frequencies of mating reflect the presence of various proportions of highfrequency mating (HFM) 'mutants' in non-mating parental populations. Indirect isolations of the hypothetical HFM 'mutants' from the original parental population by replica plating (Lederberg \& Lederberg, 1952) or other similar methods appeared, at first, to be the most promising approach to this question. That this method would be impractical, however, was indicated by an examination of the data presented in Table 1, which suggest that the hypothetical HFM 'mutant' must be very rare in the $6 \mathrm{~F} 4-1$ or $6 \mathrm{F5}-16$ parental populations because of the very low frequency of heterokaryon formation. An opposite approach was therefore adopted: indirect isolation of low-frequency mating (LFM) 'revertants' from an HFM strain which had undergone a few serial transfers. That such 'revertants' might be fairly common under these conditions was suggested by an earlier experiment, in which the frequency of heterokaryosis of the 'secondary parental isolates' was shown to decrease after several serial transfers. However, the experiment based on these premises produced unforeseen results, as represented in Table 2, Expt. 2. The frequency of heterokaryosis between the 'secondary parental isolates' 6F 4-1 A and 6F 5-16 $\mathrm{A}$ seemed to decrease up to the 8th transfer and then abruptly increased, reaching a very high value. Five single conidial isolates 
Table 2. Influence of serial transfers of high and low compatibility strains of Streptomyces fradiae on the frequency of heterokaryosis

No. of transfers

3

3

6

6

9

9

12

12

15

15

3

3

6

6

$\gamma$

7

8

8

12

13

14

15

21
Strains

6 F 4-1
6 F 5-16
6 F 4-1A
6 F 5-16A
6 F 4-1
6 F 5-16
6 F 4-1A
6 F5-16A
6 F 4-1
6 F5-16
6 F 4-1A
6 F5-16A
$6 F 4-1$
6 F5-16
$6 F 4-1 A$
$6 F 5-16 A$
$6 F 4-1$
$6 F 5-16$
$6 F 4-1 A$
$6 F 5-16 A$

6 F 4-1

6 F5-16

$6 F 4-1 A$

6 F 5-16A

6F4-1

6F 5-16

$6 \mathrm{~F} 4-1 \mathrm{~A}$

6F 5-16A

6 F 4-1

6F 5-16

6 F 4-1 A

6 F 5-16A

6 F 4-1

6 F 5-16

6 F 4-1 A

6F 5-16A

6 F 4-1A

6F5-16A

6F 4-1 A

6F5-16A

6 F 4-1 A

6F5-16A

$6 \mathrm{FA}-1 \mathrm{~A}$

6F5-16A

6F 4-1 A

6 F5-16A
No. of

Inoculum (no. of heterokaryotic Heterokaryotic conidia/plate)

colonies/plate* frequency $\times 10^{8 *}$

Experiment 1

\begin{tabular}{|c|c|c|}
\hline $\begin{array}{l}1.1 \times 10^{7} \\
5.2 \times 10^{9}\end{array}$ & $10 \cdot 0$ & $91 \cdot 0$ \\
\hline $\begin{array}{l}9.4 \times 10^{6} \\
1.9 \times 10^{9}\end{array}$ & 269 & 2800 \\
\hline $\begin{array}{l}1.4 \times 10^{6} \\
3.7 \times 10^{7}\end{array}$ & $7 \cdot 5$ & $53 \cdot 0$ \\
\hline $\begin{array}{l}1.1 \times 10^{7} \\
4 \cdot 1 \times 10^{7}\end{array}$ & 400 & 3500 \\
\hline $\begin{array}{l}3.0 \times 10^{7} \\
5.2 \times 10^{9}\end{array}$ & 22.5 & $74 \cdot 0$ \\
\hline $\begin{array}{l}2.8 \times 10^{7} \\
1.8 \times 10^{9}\end{array}$ & 65.5 & 230 \\
\hline $\begin{array}{l}6.5 \times 10^{7} \\
1.2 \times 10^{10}\end{array}$ & $13 \cdot 5$ & $20 \cdot 7$ \\
\hline $\begin{array}{l}1.4 \times 10^{7} \\
2 \cdot 7 \times 10^{8}\end{array}$ & $4 \cdot 0$ & $28 \cdot 0$ \\
\hline $\begin{array}{l}8.9 \times 10^{6} \\
9.8 \times 10^{8}\end{array}$ & $7 \cdot 5$ & $84 \cdot 6$ \\
\hline $\begin{array}{l}1.7 \times 10^{7} \\
4.8 \times 10^{8}\end{array}$ & $7 \cdot 5$ & $44 \cdot 6$ \\
\hline
\end{tabular}

Experiment 2

\begin{tabular}{|c|c|c|}
\hline $\begin{array}{l}6 \cdot 1 \times 10^{7} \\
6.3 \times 10^{7}\end{array}$ & $13 \cdot 5$ & $22 \cdot 0$ \\
\hline $\begin{array}{l}2 \cdot 8 \times 10^{7} \\
4 \cdot 3 \times 10^{7}\end{array}$ & 383 & 1370 \\
\hline $\begin{array}{l}5 \cdot 7 \times 10^{7} \\
1 \cdot 1 \times 10^{8}\end{array}$ & $8 \cdot 8$ & $15 \cdot 4$ \\
\hline $\begin{array}{l}1.1 \times 10^{8} \\
2.6 \times 10^{7}\end{array}$ & 353 & 1300 \\
\hline $\begin{array}{l}7 \cdot 7 \times 10^{7} \\
2 \cdot 3 \times 10^{7}\end{array}$ & $3 \cdot 0$ & $13 \cdot 0$ \\
\hline $\begin{array}{l}5.5 \times 10^{7} \\
6.3 \times 10^{7}\end{array}$ & 387 & 703 \\
\hline $\begin{array}{l}9 \cdot 6 \times 10^{7} \\
7 \cdot 9 \times 10^{7}\end{array}$ & $13 \cdot 8$ & $17 \cdot 4$ \\
\hline $\begin{array}{l}6 \cdot 2 \times 10^{7} \\
7 \cdot 9 \times 10^{7}\end{array}$ & 321 & 518 \\
\hline $\begin{array}{l}4.2 \times 10^{7} \\
2.1 \times 10^{7}\end{array}$ & 357 & 1700 \\
\hline $\begin{array}{l}9.0 \times 10^{6} \\
9.0 \times 10^{6}\end{array}$ & 681 & 7570 \\
\hline $\begin{array}{l}6 \cdot 0 \times 10^{7} \\
6 \cdot 1 \times 10^{7}\end{array}$ & $>5000$ & $>10000$ \\
\hline $\begin{array}{l}1 \cdot 1 \times 10^{8} \\
1.6 \times 10^{8}\end{array}$ & $>5000$ & $>5000$ \\
\hline $\begin{array}{l}6.9 \times 10^{6} \\
8.7 \times 10^{7}\end{array}$ & $>5000$ & $>80000$ \\
\hline
\end{tabular}

* Cf. Table 1 . 
were selected from each HFM parent after the 7th and 12th transfers and crossed in all possible combinations $(2 \times 25$ crosses $)$. All of these crosses exhibited a very high heterokaryotic frequency, with confluent heterokaryotic growth on the majority of plates.

\section{Interspecific mating}

To study heterokaryotic compatibility between different strains and species of Streptomyces, isolates of Streptomyces fradiae capable of high-frequency heterokaryosis were mated with other auxotrophs of $S$. fradiae and with auxotrophs of other species of Streptomyces: $7 \mathrm{~A} 25$ (S. venezuelae requiring isoleucine + valine), 4B19-1 ( $S$. griseus requiring arginine + methionine), 14D1 ( $S$. coelicolor requiring histidine + methionine), and 6F3-3 ( $S$. fradiae requiring methionine + threonine). As shown in Table 3, no heterokaryons resulted from interspecific matings. When mutant $6 \mathrm{F3}-3$ was mated with an HFM isolate of another auxotroph of $S$. fradiae, the result was a small but reproducible increase in the frequency of heterokaryosis over that observed for the two parental auxotrophs.

Table 3. Frequency of heterokaryon formation in interspecific and intraspecific mating experiments

\begin{tabular}{|c|c|c|c|c|}
\hline Strains & Species & $\begin{array}{c}\begin{array}{c}\text { Inoculum } \\
\text { (no. of } \\
\text { conidia/plate) }\end{array}\end{array}$ & $\begin{array}{c}\text { No. of } \\
\text { heterokaryotic } \\
\text { colonies/plate* }\end{array}$ & $\begin{array}{c}\text { Hetero- } \\
\text { karyotic } \\
\text { frequency* }\end{array}$ \\
\hline $\begin{array}{l}\text { 6F 4-1 } \\
6 \text { F 5-16 }\end{array}$ & $\begin{array}{l}\text { S. fradiae } \\
\text { S. fradiae }\end{array}$ & $\begin{array}{l}4.4 \times 10^{7} \\
1.5 \times 10^{8}\end{array}$ & 68.0 & 155 \\
\hline $\begin{array}{l}6 F 4-1 \\
6 F 5-16 A\end{array}$ & $\begin{array}{l}\text { S. fradiae } \\
\text { S. fradiae }\end{array}$ & $\begin{array}{l}4.4 \times 10^{7} \\
3.8 \times 10^{8}\end{array}$ & 470 & 1070 \\
\hline $\begin{array}{l}\text { 7A25 } \\
\text { 6 F5-16 }\end{array}$ & $\begin{array}{l}\text { S. venezuelae } \\
\text { S. fradiae }\end{array}$ & $\begin{array}{l}3.0 \times 10^{9} \\
1.5 \times 10^{8}\end{array}$ & 0.0 & - \\
\hline $\begin{array}{l}7 \mathrm{A25} \\
6 \mathrm{F5}-16 \mathrm{~A}\end{array}$ & $\begin{array}{l}\text { S. venezuelae } \\
\text { S. fradiae }\end{array}$ & $\begin{array}{l}3.0 \times 10^{9} \\
3.8 \times 10^{8}\end{array}$ & $0 \cdot 0$ & - \\
\hline $\begin{array}{l}4 \text { B 19-1 } \\
6 \text { F 5-16 }\end{array}$ & $\begin{array}{l}\text { S. griseus } \\
\text { S. fradiae }\end{array}$ & $\begin{array}{l}6.4 \times 10^{8} \\
1.5 \times 10^{8}\end{array}$ & 0.0 & - \\
\hline $\begin{array}{l}4 B 19-1 \\
6 F 5-16 A\end{array}$ & $\begin{array}{l}\text { S. griseus } \\
\text { S. fradiae }\end{array}$ & $\begin{array}{l}6.4 \times 10^{8} \\
3.8 \times 10^{8}\end{array}$ & $0 \cdot 0$ & - \\
\hline $\begin{array}{l}\text { 14D 1 } \\
6 \text { F 5-16 }\end{array}$ & $\begin{array}{l}\text { S. coelicolor } \\
\text { S. fradiae }\end{array}$ & $\begin{array}{l}1.5 \times 10^{8} \\
1.5 \times 10^{8}\end{array}$ & 0.0 & - \\
\hline $\begin{array}{l}14 \mathrm{D} 1 \\
6 \mathrm{F5}-16 \mathrm{~A}\end{array}$ & $\begin{array}{l}\text { S. coelicolor } \\
\text { S. fradiae }\end{array}$ & $\begin{array}{l}1.5 \times 10^{8} \\
3.8 \times 10^{8}\end{array}$ & 0.0 & - \\
\hline $\begin{array}{l}\text { 6F3-3 } \\
6 \text { F5-16 }\end{array}$ & $\begin{array}{l}\text { S. fradiae } \\
\text { S. fradiae }\end{array}$ & $\begin{array}{l}3.1 \times 10^{9} \\
1.5 \times 10^{8}\end{array}$ & 13.7 & 0.9 \\
\hline $\begin{array}{l}6 \mathrm{F3}-3 \\
6 \mathrm{F5}-16 \mathrm{~A}\end{array}$ & $\begin{array}{l}\text { S. fradiae } \\
\text { S. fradiae }\end{array}$ & $\begin{array}{l}3.1 \times 10^{9} \\
3.8 \times 10^{8}\end{array}$ & 217 & $5 \cdot 7$ \\
\hline
\end{tabular}

\section{DISCUSSION}

The experimental data indicate that through the selection of parental-type conidia produced by heterokaryotic colonies, the frequency of heterokaryosis can be significantly increased over that characteristic for the original parents. 
Two possible mechanisms for this phenomenon were evaluated: (1) greater residual mycelial growth of the secondary parental-type conidia on the selective medium, providing more opportunity for hyphal contact; (2) a greater frequency of anastomosis upon hyphal contact. Operation of the first mechanism appears unlikely, since comparative microscopic examination indicated that low- and high-frequency mating types were similar in frequency of conidial germination and in mycelial development, when grown separately or in mixed culture. At the present time, there are no obvious means of making direct observation or measurement of the frequency of hyphal fusion (anastomosis) in Streptomyces fradiae because of the rare occurrence of this process. The high frequency of cellular fusion in $S$. scabies reported by Gregory (1956) might present advantages from this aspect.

Some hint as to the nature of the inheritance of heterokaryotic compatibility can be obtained from the experiments in which the stability of the mating behaviour after serial transfer was studied. Table 2, Expt. 1, indicates that the frequency of heterokaryon formation remained high through several transfers, gradually decreasing after 9 transfers (corresponding to approximately 150 nuclear divisions and respective cytoplasmic growth), to the low value characteristic of the original mutants only after 12 transfers. If the number of nuclear divisions is considered equivalent to the number of cell divisions, as in the case of the Eubacteriales, loss of the ability to form heterokaryons takes place much too slowly to be caused by cytoplasmic dilution. On the other hand, this gradual decline in heterokaryotic frequency can be explained more readily in terms of a mutation and selection mechanism. If there were a slow rate of back mutation from high- to low-frequency mating type, provided the low-frequency mating type had a selective advantage, the composition of the high-frequency mating-type population would slowly change to that of the predominantly low-frequency mating-type parental strains.

Further confirmation of the mutation hypothesis is provided by Expt. 2 (Table 2). The fluctuation in the heterokaryotic frequency might be construed to represent successive population shifts, at first favouring LFM and later HFM mutants. This second shift of the whole population toward higher heterokaryotic frequency after the 12th transfer was accompanied by loss of the capacity of the strains to sporulate and a consequent decrease in the inoculum size with each successive transfer.

Attempts to derive strains demonstrating even higher frequencies of heterokaryotic colony formation through successive heterokaryotic mating and isolation of tertiary parental-type conidia failed to produce strains of higher mating frequency. On the other hand, higher heterokaryotic frequencies were observed after serial transfers in Expt. 2 (Table 2) and upon single conidium isolation during the same experiment. Further studies on the ability of HFM strains to form heterokaryons with strains of the same species but of different origin may prove helpful in the evaluation of heterokaryotic compatibility as a taxonomic criterion, since in no case were interspecific matings successful. 
This study was supported in part by grant No. 3333 from the National Science Foundation. One of the authors D.H.B. was a Waksman-Merck Postdoctoral Fellow.

\section{REFERENCES}

Beadle, G. W. \& Coonradt, V. L. (1944). Heterokaryosis in Neurospora crassa. Genetics, 29, 291.

Bradley, S. G. \& Lederberg, J. (1956). Heterokaryosis in Streptomyces. $J$. Bact. $72,219$.

Braendle, D. H. \& Szybalski, W. (1957). Genetic interaction among streptomycetes: heterokaryosis and synkaryosis. Proc. nat. Acad. Sci. Wash. 43, 947.

Dodge, B. O. (1942). Heterokaryotic vigor in Neurospora. Bull. Torrey bot. Cl. 69, 75.

Gregory, K. F. (1956). Hyphal anastomosis and cytological aspects of Streptomyces scabies. Canad. J. Microbiol. $2,649$.

Hansen, H. N. (1938). The dual phenomenon in imperfect fungi. Mycologia, 30, 442.

Ishitani, C. \& Sakaguchi, K. (1956). Hereditary variation and recombination in Koji-molds (Aspergillus oryzae and Asp. sojae). V. Heterocaryosis. J. gen. Appl. Microbiol. 2, 345.

LeDerberg, J. \& LeDerberg, E. M. (1952). Replica plating and indirect selection of bacterial mutants. J. Bact. 63, 399.

Papazian, H. P. (1950). Physiology of the incompatibility factors in Schizophyllum commune. Bot. Gaz. 112, 143.

Ponteconvo, G. (1946). Genetic systems based on heterokaryosis. Cold Spr. Harb. Symp. quant. Biol. 11, 193.

Raper, J. R. \& San Antonio, J. P. (1954). Heterokaryotic mutagenesis in Hymenomycetes. I. Heterokaryosis in Schizophyllum commune. Amer. J. Bot. 41, 69.

Sermonti, G. \& Spada-Sermonti, I. (1956). Gene recombination in Streptomyces coelicolor. J. gen. Microbiol. 15, 609.

Szybalski, W. \& Braendle, D. H. (1956). Genetic recombination in Streptomyces. Bact. Proc. 48. 